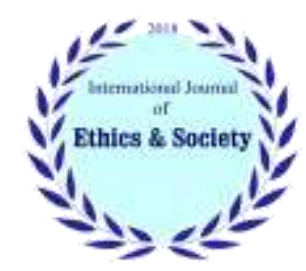

International Journal of Ethics \& Society (IJES)

Journal homepage: www.ijethics.com

Vol. 3, No. 2 (2021)

\title{
Unethical Consequences in the Financial Reporting Process
}

\section{Zhu Chuang}

Dept. of Management Sciences, Faculty Management, University of Science and Technology, China

\section{Abstract}

Background: The discussion of the consequences of unethical behavior in the financial reporting process, in itself, leads to other socio-economic consequences. This article explores how financial reporting immorality triggers a flood of other unintended consequences and has detrimental effects on everyone in a community. It is also explained that identifying and finding the causes of social and economic harms is preferable to solving the problems that follow because, as the saying goes, prevention is better than cure.

Conclusion: Since the reliability and reliability of financial reports has a direct relationship with the moral health of its producers, it seems necessary to find the root and cause of immoral behavior, meet the needs, develop laws and deterrent penalties. And also spread values and virtues in society and the workplace. This process will enable accountants to withstand the negative pressures of the workplace, carnal desires, and financial and economic problems, and to choose the path of ethics in two ways.

Keywords: Economic and social consequences, Reporting consequences, Immoral behavior

\section{Introduction}

Along with the emergence of the concept of a happy life and the primitive human thinking of the two concepts of "good" and "evil", philosophers brought to the fore different moral views in human societies. Many philosophers make every effort to answer questions such as, how should man behave and what is moral behavior? Has been steadfast. When we talk about ethics and ethical values in financial matters, we mean concerns about issues such as conflicts of interest, disclosure of confidential information and misrepresentation of financial

* Corresponding Author: Email: zchuang34@gmail.com

Received: 12 Apr 2021

Accepted: 01 Jun 2021 
statements, and other similar measures to protect the financial interests of some people.

After many years of moral transformation, today human beings are faced with complex and complicated problems and issues that are the result of immoral behaviors such as injustice, fraud, discrimination, deception, bias and many other things that are the future of socio-economic life. It threatens the human race. All human beings face moral dilemmas. Accountants are no different from other human beings. They face many situations in their work life. Situations that are tempted to do something immoral.

Accounting ethics was first introduced by Luca Piccioli and later developed by government groups, professional organizations and independent companies, and was introduced as a set of rules that an individual uses to control his behavior and Its criteria are whether the actions are "right or wrong" (1). Francis points out that accounting choices are an activity in the realm of moral insight because of the potential impact they have on society. Accounting is explicitly important from the perspective that it can change the world, it can overshadow the lives of others (2). Therefore, accountants, as financial reporting specialists, need to adhere to a code of professional conduct to prepare reliable financial reports.

In accounting, the main source of ethical principles to which it refers is the code of professional conduct. However, the mere existence of a code of professional conduct does not necessarily mean a commitment to it. In addition, no code of professional conduct can address any potential moral issues faced by the professional. $\left({ }^{\top}\right)$

In this article, it is believed that the main source of adverse economic and social consequences is the neglect of ethical values in the financial reporting process. Undoubtedly, identifying and finding the causes of social and economic harms is preferable to solving the problems that follow, because, as the saying goes, prevention is better than cure.

Immoral consequences in the financial reporting process
The debate over the consequences of unethical behavior in the financial reporting process in itself leads to other socio-economic consequences. It goes on to explain how financial reporting immoralities cause a flood of other adverse consequences and have detrimental effects on everyone in a society. Some of these consequences are:

\section{Loss of public trust in accountants and ac-} counting products

Society trust is one of the vital components of today's civilization, which means people trusting a certain group of other people or trusting their products. This trust can be sustained as long as the rights and interests of members of society are fairly protected, and it is damaged when an individual or group of individuals unfairly and fraudulently prioritizes their own interests over the interests of others in society.

In recent years, accountants and auditors of large companies such as Enron, Tyco, Rite Aid, Word Com, Grace, Cendant, Sun Beam, Livent, and Anderson have resorted to accounting fraud to report higher profits and deceive investors. Have been audited. In these companies, ethics has been sacrificed for profit, and the misconduct of accountants and auditors has led to a crisis and public distrust of accounting products (4).

It seems that the inefficiency of the capital market in relation to accounting information in many countries is due to people's lack of trust in corporate accounting information. The decline of the position of accountants and auditors in society may cause information users to refrain from referring to them for their financial and economic decisions because they consider accountants to be unreliable and unreliable people. The community's lack of trust in accountants and their products in the long run will reduce the demand for accounting and auditing work, and the community will likely turn to other available and valid information to make decisions. Lack of public trust destroys the dignity of the accounting and auditing profession, which alone will lead to huge and irreparable costs for society.

2. Ignoring the rights of the government and
consequently reducing social welfare 
The government, as one of the stakeholders of the business unit, has a right to the interests of the companies. According to the law, economic units are obliged to transfer part of their annual revenues to the government, because the government has provided the security for trade, and in fact, in the absence of government bodies and organs, safe and regular trade will not be possible. Unethical financial reporting will typically disregard the rights of many stakeholders, including the government.

The past tax structure in Iran is shaped in such a way that tax revenues constitute a small share of total government revenues. Due to the existing shortcomings, especially the unrealistic declaration of income by taxpayers and consequently tax evasion, every year we see the failure to achieve social justice and the projected goals of the government (5). If the managers and accountants of companies manipulate the calculation of taxable profit accounting methods and ignore ethical values, the government and consequently all members of society will suffer. Because the tax received from the people of a society, again but in a different way goes back to the people themselves. It is worth noting that in the government's financial system, first all revenues are deposited in the treasury account and then, with the approval of the budget, the revenues are spent on the designated expenditures. Obviously, as government revenues increase, so does the share of each member of society in government revenues. However, if taxpayers refuse to report and provide accurate financial information and try to deceive government officials, it will reduce public welfare and social justice. Immorality in financial reporting, the preparation of unrealistic tax returns and the lack of a tax culture in the minds of financial information providers may, for years, keep the government in the seat of the oil-based economy and, unlike the financial system of developed countries, only through sales. Underground resources can make up for most of their lack of funding. It is possible that most experts and experts in recent decades have warned of the depletion of underground resources in the near future (6-8).

\section{Increasing court costs and lawsuits and re- ducing the value of the company}

In cases where companies determine the remuneration of their managers based on the company's net profit, based on the reward hypothesis of positive accounting theories, it is predicted that in this situation, managers to increase their remuneration and wages from certain accounting methods. They use that to transfer the profit of the future period to the current period. Ethical and human values are often ignored in the choice of these methods. These immoral behaviors of managers, which are purely opportunistic and focus only on their personal interests, are likely to lead landlords to file lawsuits against managers to prove their illegal actions. Announcing the news of the owners' complaint against the managers of a company is considered as bad news in the market for that company. In this situation, it will be clear to the market that the people responsible for preparing the financial statements are unreliable and unreliable people. However, how can users rely on the information provided by these individuals? Tensions and conflicts between owners and managers will bear more of the costs of missed opportunities for production and competition than the financial costs of litigation. This is likely to reduce the value of the company's stock in the capital market and ultimately lead to a decrease in the value of the company and the wealth of shareholders (9).

\section{Loss of financial resources, bankruptcy and collapse of business units}

Many users, including banks, base their decisions on corporate accounting information and act on that information. Providing incorrect information leads to incorrect decisions. For example, imagine a company that is not in a good financial position and decides to display its corporate debt ratio on the balance sheet in an unethical way in order to receive the facility, in order to be able to receive the facility. In this case, the bank or lending institution may decide to lend to the company based on this incorrect information. With this action, the company's management has not only increased its previous debt, but will probably lose the ability to pay the interest amount and repay the original loan on the due date. Also, by delaying the payment of loan installments, the penalties for annual bank arrears will increase their debt. In this case, the creditor may acquire the 
documents he has received from the company as a supporter through the judicial authorities. This situation is likely to bring the company to the brink of bankruptcy. Customers may become aware of the company's financial distress and, for fear of losing their parts and equipment manufacturer, enter into future contracts with competing companies, and many other issues (10-12).

Most experts consider only financial and economic problems as the main cause of companies' bankruptcy, while with a little reflection, it can be understood that the main root of this factor can be the unethical decisions and behaviors of company managers. The collapse and destruction of many companies has many other social and economic consequences. Many large companies affect the lives of thousands. Any unfavorable performance of these companies, in addition to the wealth of owners and suppliers, also affects the job security of their employees. Bankruptcy, for example, leads to the unemployment of many of their employees, and the phenomenon of unemployment itself is a direct path to many social ills, the consequences of which, such as poverty, addiction and divorce, can be a serious threat to the destruction of human civilization.

5. Codifying and regulating new and restrictive laws and regulations

Sometimes the immoral behaviors of individuals in a society can also have favorable and favorable consequences. Perhaps one of the best consequences of immorality is the enactment of new laws and regulations to support future generations and a powerful stimulus to control and prevent the recurrence of crime. For example, in the case of financial reporting scandals in recent decades, we can refer to the passage of the Sarbanes-Oxel 10 Act. Under the law, heavier and more severe fines are imposed for fraudulent financial activities. The bill became known as the Sarbanes-Oxley 2002 Act, or Sarbanes, as a result of the passage of the US federal law as a result of the support of Paul Sarbanes in the US Senate and Michael J. Oxley, a Republican in the US House of Representatives (13-14).

Immoral behavior in the financial reporting process will eventually affect the producers and approvers of financial reports, which will result in severe penalties and irreparable penalties. If we are to expand the discussion to a level beyond the material world, then there are metaphysical issues that have been discussed in most religions, which, in order to be beyond the scope of this article, we will not address. It is preferred that the study be postponed to another time and it should be left to qualified researchers to explain.

\section{Conclusion}

Whenever value issues are raised, there are always a number of proponents and opponents who, in order to solve the existing problems and problems, enter the field of discussion along with the value discourse, which is a natural thing. In any case, from the point of view of this article, in order to solve moral problems and problems, finding their root and existence is the first and most important step to neutralize its effects, because, as the famous saying goes, water must be removed from the source.

Therefore, the reasons for all immoral and inhumane behaviors in the accounting and financial reporting process do not seem to be outside the individual spheres and environmental conditions:

- Financial and economic problems of financial statement preparers

- Lack of supervision over the correct implementation of laws and lack of appropriate deterrents

- Environmental pressures governing the business unit, such as the requirements of credit agreements

- Weakness of faith and human beliefs of accountants and greed of financial report preparers

Of course, the correct prioritization of the above cases requires field research and operational research, which it is suggested that future researcher's study and test.

Since the reliability and reliability of accounting products is directly related to the moral health of its suppliers, in the second step, it is necessary to 
meet the needs, develop laws and deterrent punishments, and also expand the values and virtues in society and the workplace. To institutionalize the human and moral spirit in accountants. This process will enable accountants to withstand the negative pressures of the workplace, emotional cravings, and financial and economic problems.

Therefore, it is necessary to choose the path of morality in the two ways of carnality and to make conscientious and humane decisions in difficult situations, for a simple reason: "To support the future life of our children."

\section{Ethical Consideration}

Ethical issues (such as plagiarism, conscious satisfaction, misleading, making and or forging data, publishing or sending to two places, redundancy, etc.) have been fully considered by the writers.

\section{Acknowledgement}

Thanks to all colleagues and students who patiently shared their knowledge in this research.

\section{References}

1. Appah E, Ogbonna GN (2012). Effect of ethical accounting standards on the quality of financial reports of banks in Nigeria. Current Research Journal of Social Sciences, 4 (1): 6978.
2. Francis J (1990). After virtue? Accounting as a moral and discursive practice. Accounting, Auditing \& Accountability Journal, 3 (3): 5-17.

3. Kocet MM (2006). Ethical challenges in a complex world: highlights of the 2005 ACA code of ethics. Journal of Counseling \& Development, 84(1): 23-31.

4. Appah E (2010). Ethical accounting standards and societal expectations. International Journal of Society Policy, 7(2): 53-63.

5. Uysal Z (2010). Business ethics research with an accounting focus. Journal of Business Ethics, 93:137-160.

6. Jones M, Felps W, Gregory A (2007). Ethical theory and stakeholder related decisions: the role of stakeholder culture. Academy of Management Review, 32(1): 137- 155.

7. Merchant KA, Rocknes J (1994). The ethics of managing earnings: An empirical investigation. Journal of Accounting and Public Policy, 13 (1): 79-94.

8. Elias RZ (2002). Determinants of earnings management ethics among accountants. Journal of Business Ethics, 40 (1): 33-45.

9. Dyreng SD, Mayew WJ, Williams CD (2012). Religious social norms and corporate financial reporting. Journal of Business Finance and Accounting, 39: 845-875.

10. Allport GW, Ross JM (1967). Personal religious orientation and prejudice. Joumal of Personality and Social Psychology, 5: 423 - 443.

11. Sunstein CR (1996). Social norms and social rules. Columbia Law Review, 96 (4): 903-968.

12. McGuire ST, Omer TC, Sharp NY (2012). The impact of religion on financial reporting irregularities. The Accounting Review, 87(2): 645- 673.

13. Cialdini RB, Goldstein NJ (2004). Social influence: Compliance and conformity. Annual Review of Psychology, 55 (1): 591-621.

14. Weaver GR, Agle BR (2002). Religiosity and ethical behavior in organizations: A symbolic Interaction's perspective. Academy of Management Review, 27 (1): 77-97. 